\title{
Organic Cation Transporter 3 (Slc22a3) Is Implicated in Salt- Intake Regulation
}

\author{
Vincent Vialou, ${ }^{1}$ Anne Amphoux, ${ }^{1}$ Ronald Zwart, ${ }^{2}$ Bruno Giros, ${ }^{1}$ and Sophie Gautron ${ }^{1}$ \\ ${ }^{1}$ Institut National de la Santé et de la Recherche Médicale U513, Faculté de Médecine, 94010 Créteil, France, and 2Department of Molecular Genetics, The \\ Netherlands Cancer Institute, 1066CX Amsterdam, The Netherlands
}

\begin{abstract}
Organic cation transporters (OCTs) are carrier-type permeases known to participate in general detoxification functions in peripheral tissues. Previous in vitro studies have suggested that OCTs ensure Uptake ${ }_{2}$, a low-affinity, corticosteroid-sensitive catecholamine removal system, which was characterized initially in sympathetically innervated tissues. Although the presence of both Uptake ${ }_{2}$-like transport and most OCT subtypes has also been demonstrated in the brain, the physiological role of this family of transporters in CNS remained totally unknown. In the present work, we show that the OCT3 transporter is found throughout the brain and highly expressed in regions regulating fluid exchange, including circumventricular organs such as area postrema and subfornical organ (SF0), and in other structures implicated in the sensing of changes in blood osmolarity and regulation of salt and water ingestion. 0CT3/Slc22a3-deficient mice show an increase in the level of ingestion of hypertonic saline under thirst and salt appetite conditions, as well as alterations of the neural response in the SFO after sodium deprivation, as monitored by Fos immunoreactivity. This work demonstrates that the presence of OCT3 is critical for the balanced neural and behavioral responses to environmentally induced variations in osmolarity and provides for the first time physiological evidence of the importance of OCTs for CNS function.
\end{abstract}

Key words: organic cation transporter; Uptake ${ }_{2}$; circumventricular organs; salt appetite; c-fos; monoamine

\section{Introduction}

Organic cation transporters (OCTs) are carrier-type permeases that participate in the elimination of a variety of cationic substances, physiological compounds, and xenobiotics in tissues such as kidney, liver, and placenta (Koepsell, 1998). In addition to this general detoxification function, the OCT family has also been proposed to ensure Uptake ${ }_{2}$, a catecholamine removal system found in peripheral tissues with sympathetic innervation. Uptake $_{2}$ is a sodium- and chloride-independent, low-affinity, high-capacity transport system initially described in heart, smooth muscle, and glandular cells (Iversen, 1965). Contrary to sodium-driven, high-affinity neuronal Uptake ${ }_{1}$ Uptake $_{2}$ can be inhibited by corticosteroids and $O$-methylated catecholamines as well as cyanin-related compounds (Trendelenburg, 1988; Friedgen et al., 1996; Wu et al., 1998). The main OCT subtypes (OCT1, OCT2, and OCT3) isolated these last few years in humans and rodents display pharmacological profiles that match these general characteristics (Grundemann et al., 1997, 1998a,b; Busch et al., 1998; Wu et al., 1998; Hayer-Zillgen et al., 2002).

Received Nov. 21, 2003; revised Feb. 4, 2004; accepted Feb. 7, 2004.

V.V. and A.A. are recipients of fellowships from the French Ministry for Research and the Institut de Recherches Servier, respectively. Financial support was provided by the Institut National pour la Santé et la Recherche Scientifique. We thank Denise Barlow (Institut für Molekularbiologie der ÖAW, Vienna) for kindly providing the OCT3 knock-out mice, Azhour Lahdar and Martine Muffat-Joly (Centre d'Explorations Fonctionnelles Intégré, Faculté de Médecine Xavier Bichat, Paris) for the evaluation of electrolyte levels in plasma, and Catalina Betancur for stimulating discussions and comments on this manuscript.

Correspondence should be addressed to Dr. Sophie Gautron, Institut National de la Santé et de la Recherche Médicale U513, Faculté de Médecine, 8 rue du Général Sarrail, 94010 Créteil, France. E-mail: gautron@im3.inserm.fr. DOI:10.1523/JNEUROSCI.5147-03.2004

Copyright $\odot 2004$ Society for Neuroscience $\quad$ 0270-6474/04/242846-06\$15.00/0
A transport system very similar to Uptake ${ }_{2}$ has also been identified previously in the brain. Accumulation of noradrenaline (NA) and of the model substrate isoprenaline, displaying lowaffinity kinetics and the overall characteristics of peripheral Uptake $_{2}$, was demonstrated in rat cerebral cortex slices (Hendley et al., 1970; Wilson et al., 1988). The existence of this central Uptake $_{2}$ system was further supported by a report showing that the residual $\mathrm{MPP}^{+}$uptake observed after suppression of Uptake ${ }_{1}$ by cocaine was sensitive to the selective Uptake ${ }_{2}$ inhibitor disprocynium24 (Russ et al., 1996). In agreement with these findings, most OCTs have been found expressed in murine or human brain by Northern blotting or RT-PCR, although at a low level (Gorboulev et al., 1997; Grundemann et al., 1997, 1998b; Busch et al., 1998; Wu et al., 1998). Until now, however, the role of these OCT subtypes and, more generally, the physiological relevance of Uptake $_{2}$ in the CNS, remained unknown.

Although OCT1 and OCT2 seem to be restricted mainly to kidney, liver, and intestine, OCT3 shows a relatively broader tissular distribution, including heart and placenta. It also shows a specific profile of graded sensitivity toward various corticosteroids and disprocynium 24 . On the grounds of these observations, it was inferred that OCT3 must account in great part for Uptake ${ }_{2}$ transport (Grundemann et al., 1998b; Wu et al., 1998). This significant contribution in the handling of organic cations at the periphery was confirmed recently in mice invalidated for the OCT3/Slc22a3 gene (locus name Slc22a3) that show impaired Uptake $_{2}$ activity in heart and in embryos (Zwart et al., 2001). Whether this transporter could participate in specific neurobiological functions had nevertheless not been explored. In the present work, we show that OCT3 is found throughout the brain 
and highly expressed in regions regulating fluid exchange, including several circumventricular organs (CVOs). We provide evidence for a major role of this transporter in CNS function by demonstrating modified salt-intake regulation in OCT3/Slc22a3deficient mice.

\section{Materials and Methods}

Animals. OCT3/Slc22a3-deficient mice were generated previously by homologous recombination (Zwart et al., 2001). Animals were housed in an animal care facility with a $12 \mathrm{hr}$ light/dark cycle with food and water available ad libitum unless stated otherwise. Heterozygous mice were bred to generate wild-type and knock-out littermates, and 8- to 12-weekold mice were used for the experiments. Animal care and maintenance were in accordance with the guidelines of the European Convention for the Protection of Vertebrate Animals.

Antibodies. Rabbit polyclonal antibodies were raised and affinity purified against the OCT3 peptide SEITVTDEEVSNPSC conjugated with KLH (Agro-Bio). Antibodies directed against cellular markers neuronal nuclear antigen (NeuN), glial fibrillary acidic protein (GFAP), synaptophysin, and vesicular glutamate transporter 1 (VGLUT1), and Cy3conjugated secondary antibodies were from Chemicon International (Temecula, CA). FITC-conjugated secondary antibodies were from Molecular Probes (Eugene, OR). c-Fos and biotinylated donkey anti-goat antibodies were from Santa Cruz Biotechnology (Santa Cruz, CA).

Immunohistochemistry. Adult male Sprague Dawley rats or mice were anesthetized and perfused intracardially with $4 \%$ paraformaldehyde in PBS. Dissected brains were postfixed by immersion during $4 \mathrm{hr}$ and cryoprotected with $30 \%$ sucrose in PBS. Cryostat brain sections $(10 \mu \mathrm{m})$ or transfected human embryonic kidney (HEK) 293 cells were fixed with $4 \%$ paraformaldehyde in PBS. After preincubation in PBS containing $0.2 \%$ gelatin and $0.25 \%$ Triton $\mathrm{X}-100$, sections were incubated with OCT3 antibodies (at 1:400 dilution) in the same buffer and then with Cy3- or FITC-conjugated secondary antibodies (at 1:1600 and 1:2000 dilutions). For double-labeling experiments, antibodies directed against GFAP, NeuN, synaptophysin, or VGLUT1 (at dilutions 1:400, 1:100, $1: 3000$, and 1:10,000, respectively) were incubated with OCT3 antibodies and revealed with secondary FITC- or Cy3-coupled antibodies. For c-Fos-immunohistochemistry, mutant and control mice were placed on a low-sodium diet during $24 \mathrm{hr}$ and injected with furosemide, and brains were processed as described above and cut coronally into $40-\mu \mathrm{m}$-thick serial sections. Immunostaining was performed with a goat anti-Fos polyclonal antibody at 1:1000 dilution in presence of $0.3 \%$ Triton X-100 and then processed with biotinylated donkey anti-goat IgG antibodies and $\mathrm{ABC}$ reagents (Vector Laboratories, Burlingame, $\mathrm{CA}$ ). Fosimmunopositive cells were quantified in a set of characteristic and comparable sections of the subfornical organ (SFO) and the organum vasculosum laminae terminalis (OVLT) and expressed as the average number of positive nuclei present per square millimeter.

Cell culture. HEK 293 cells were maintained at $37^{\circ} \mathrm{C}$ in a humidified atmosphere $\left(5 \% \mathrm{CO}_{2}\right)$ in DMEM supplemented with $10 \%$ FCS, penicillin, and streptomycin (Invitrogen, Gaithersburg, MD). Cells were transfected with constructs containing OCT cDNAs in a pCR3 vector (Stratagene, La Jolla, CA) using Fugene6 (Roche, Hertforshire, UK) according to the manufacturer and processed $48 \mathrm{hr}$ later for immunocytochemical studies.

Dehydration-induced aversion to hypertonic saline. Dehydrationinduced aversion to hypertonic saline $(0.3 \mathrm{M} \mathrm{NaCl})$ was assessed in the home cages with a two-bottle preference test. Mice were trained to drink water from two bottles during 1 week. A pretest was then performed with mice presented with a choice between $0.3 \mathrm{M} \mathrm{NaCl}$ or water, and fluid intake was measured for $6 \mathrm{hr}$ (10 A.M. to 4 P.M.). The following day, bottles were removed, and mice were left with only dry food for $24 \mathrm{hr}$. Salt and water bottles were then put back, and intake was measured again for $6 \mathrm{hr}$.

Sodium depletion-induced salt appetite test. Before testing, mice were trained to drink water from two bottles during 1 week. On the day before sodium depletion, mice were presented with a choice between water and $0.3 \mathrm{M} \mathrm{NaCl}$. On the first day, mice were injected twice (10 A.M. and 4
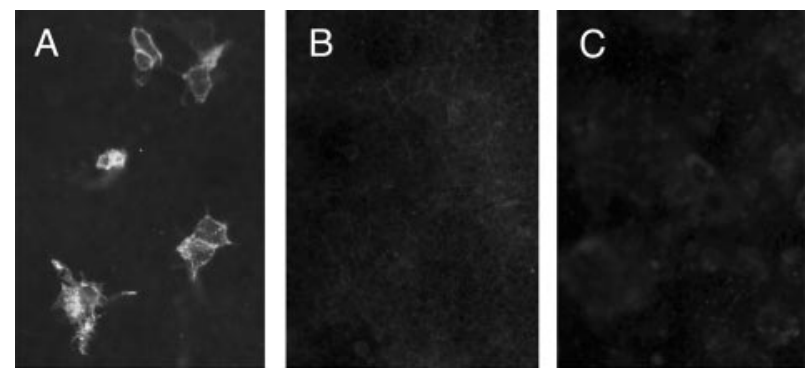

Figure 1. Specificity of the OCT3 antibodies. HEK 293 cells were transfected with a PCR30CT3 construct $(A)$, a PCR3 vector alone $(B)$, or a PCR3-0CT1 construct $(C)$, immunostained with the $0 \mathrm{CT} 3$ antibodies, and revealed with fluorescent secondary antibodies.

P.M.) with saline $(0.9 \% \mathrm{NaCl})$. At 10 A.M., the bottle of $0.3 \mathrm{M} \mathrm{NaCl}$ was withdrawn, and the normal diet was replaced with sodium-depleted food (Usine d'Alimentation Rationnelle). On the following day at 10 A.M., mice were given a choice between water and $0.3 \mathrm{M} \mathrm{NaCl}$, and liquid intake was measured at 12 A.M., 2 P.M., and 4 P.M. Subsequently, a similar protocol was performed with the same animals, with furosemide injections $(0.6 \mathrm{mg})$ instead of saline and a sodium-depleted diet. Finally, the same protocol was performed with furosemide injections associated with a normal sodium-containing diet to evaluate the effect of sodiumdepleted food. In a series of dehydrated or sodium-deprived animals, blood was collected, and the concentration of electrolytes in plasma was evaluated.

\section{Results}

\section{The OCT3 transporter is highly enriched in} circumventricular organs and found in neurons throughout the brain

Antibodies were raised and affinity purified against a synthetic peptide corresponding to a region of the rodent OCT3 protein diverging from other OCT subtypes on the basis of sequence information retrieved from databanks. The specificity of these antibodies was evaluated by transient transfection of OCTexpressing constructs in cultured cells, followed by immunofluorescent cytochemistry (Fig. 1). These experiments show that the OCT3 antibodies strongly label OCT3-transfected HEK 293 cells (Fig. $1 A$ ) but not mock-transfected (Fig. $1 B$ ), OCT1-transfected (Fig. 1C), or OCT2-transfected (data not shown) cells. The distribution of OCT3 was next investigated by immunohistochemistry on rat brain sections. Marked expression of OCT3 was observed in several regions located at the blood-brain interface, in particular several CVOs. Specifically, strong OCT3 labeling was found in the area postrema (AP) (Fig. 2A) and the SFO (Fig. 2B). In these two structures, OCT3 was found in neurons, as demonstrated by double-labeling experiments with antibodies directed against the neuronal protein NeuN (shown in Fig. $2 C$ for the SFO). In addition, ependymal cells of the subcommissural organ (SCO) (Fig. 2D) were clearly labeled, as was the pineal gland (Fig. $2 E$ ). In this latter structure, OCT3 was confined exclusively to pinealocytes, as shown by colabeling with antibodies directed against VGLUT1 (Morimoto et al., 2003), a transporter specifically expressed in these cells (Fig. $2 F$ ). In these CVOs, OCT3 was never found colocalized with nerve terminals (labeled with antisynaptophysin antibodies) or with astrocytes (labeled with antiGFAP antibodies). Choroid plexus and ependymal cells in some areas lining the ventricles also appeared strongly labeled by OCT3 antibodies.

In addition to these highly labeled structures, OCT3 was found throughout the brain, as illustrated for some regions in Figure 2: in the forebrain in frontal cortex $(G, H)$, in magnocellular and parvocellular portions of hypothalamic paraventricular 

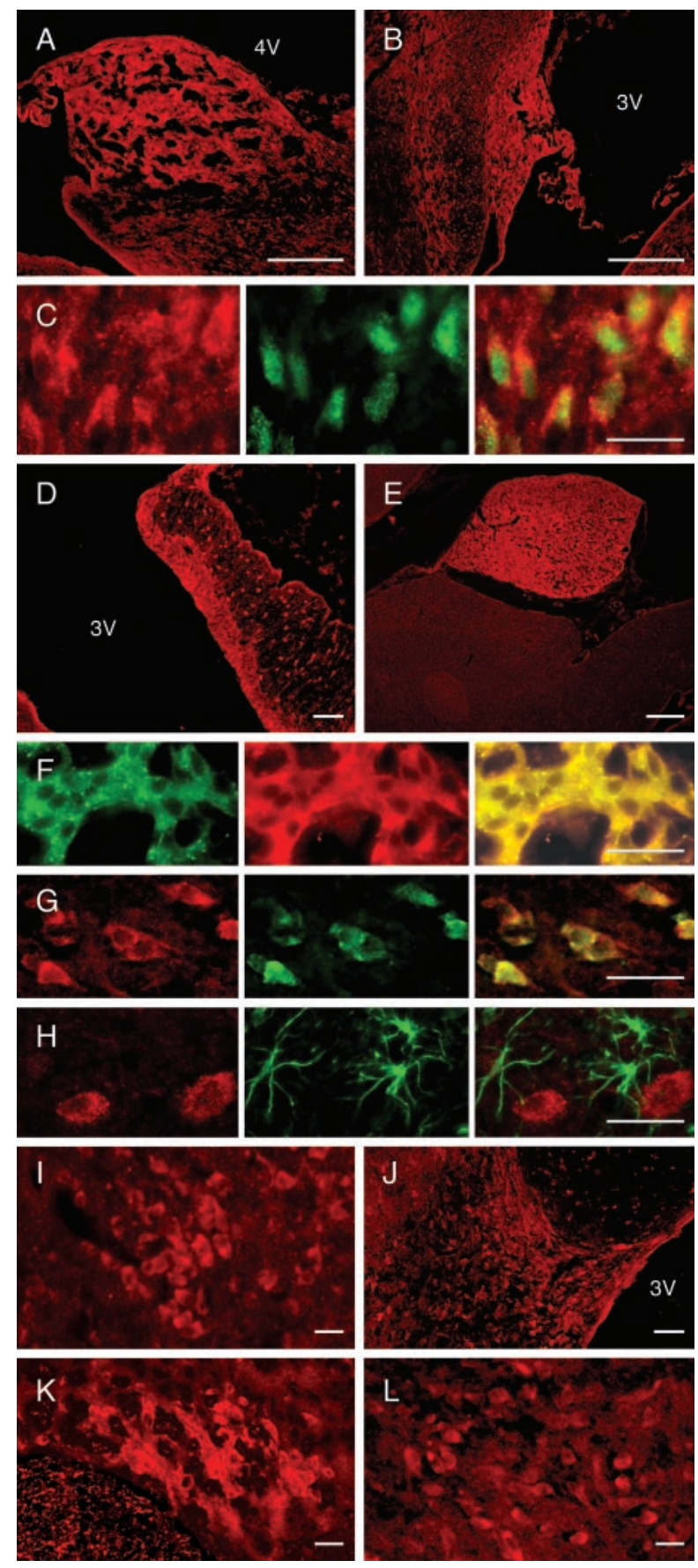

Figure 2. The OCT3 transporter is highly expressed in several CVOs and found throughout the brain. Sections of rat brain were cut sagittally, except in $K$, which was cut frontally, stained with OCT3 antibodies, and revealed by immunofluorescence. High expression of OCT3 is shown in AP $(A)$, in SFO $(B)$, in neurons of this structure, as shown by double-labeling with 0 CT3 antibodies (red) and neuronal marker NeuN antibodies (green) $(C)$, in SCO $(D)$, in the pineal gland $(E)$, and in pinealocytes of this structure as shown by double-labeling of OCT3 (green) with pinealocyte marker VGLUT1 (red) ( F). Expression of OCT3 was also seen in frontal cortex $(G, H)$, PVN (lateral magnocellular division) ( $I$ ), MPO ( $)$, SON $(K)$, and SOL (L). Colocalization of OCT3 (red) with $\operatorname{NeuN}(G)$, but not with astrocyte marker GFAP $(H)$ (green), is shown for frontal cortex. For double-labeling experiments, merged pictures are shown on the right. Scale bars: $A, B, E, 100$ $\mu \mathrm{m} ; D, J, 20 \mu \mathrm{m} ; C, F-I, K, L, 10 \mu \mathrm{m}$.

nuclei (PVN) $(I)$, in medial preoptic nuclei (MPO) $(J)$, in supraoptic nuclei $(\mathrm{SON})(K)$ and several thalamic nuclei; in the brain stem in solitary tract nucleus (SOL) nuclei $(L)$, substantia nigra, raphe nuclei, and locus coeruleus, as well as in pyramidal

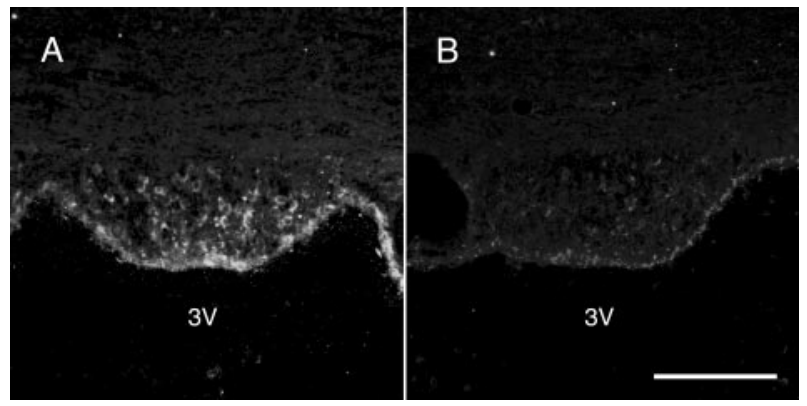

Figure 3. The OCT3 transporter is highly expressed in SF0 of wild-type but not OCT3/SIc22a3 mutant mice. Frontal sections of wild-type $(A)$ and mutant $(B)$ mouse brain were stained with OCT3 antibodies and revealed by immunofluorescence. Scale bar, $50 \mu \mathrm{m}$

cells of hippocampus and Purkinje cells of the cerebellum. Colabeling experiments with antibodies directed against either the neuronal marker NeuN (Fig. $2 G$ ) or the astrocyte specific marker GFAP (Fig. $2 H$ ) confirmed that in most brain regions a majority of neurons express OCT3. In astrocytes, in contrast, no expression of OCT3 was detected.

A very similar distribution profile, with preferential expression of OCT3 in the CVOs, was also found in mouse brain. This is illustrated in Fig. $3 A$, which shows strong labeling of the SFO with OCT 3 antibodies in wild-type mouse brain sections. This labeling was markedly decreased in the SFO of OCT3-deficient mice, further demonstrating the specificity of our antibody (Fig. 3B).

OCT3/Slc22a3-deficient mice show alteration of salt-intake behavior under thirst and salt appetite conditions

OCT3 is highly expressed in two CVOs, AP and SFO, and, at a lower level, in several structures (SON, MPO, PVN, and SOL) implicated in sensing changes in blood osmolarity and regulation of salt and water ingestion (Ferguson and Bains, 1996; Bourque and Oliet, 1997; Johnson and Thunhorst, 1997; Fitzsimons, 1998). To assess the functional participation of OCT3 in these osmoregulatory circuits, we searched in OCT3 mutant mice for alterations of the activity of these structures and for perturbations of salt-intake behavior. In dehydrated conditions, animals tend to compensate by ingesting a large quantity of water and avoiding hypertonic saline $(0.3 \mathrm{M} \mathrm{NaCl})$. We evaluated the preference for water versus hypertonic saline before and after $24 \mathrm{hr}$ of water deprivation in wild-type and mutant mice. In basal conditions (water-satiated and normal diet), total liquid intake (water plus hypertonic saline) did not differ between the two genotypes, nor did saline intake (Fig. 4). After dehydration, both groups showed a more than twofold increase in total liquid intake, but, in addition, the OCT3 mutant mice showed a significant increase in saline intake compared with wild-type mice (Fig. $4 A, B$ ).

In a second set of experiments, salt depletion was provoked by administration of the diuretic furosemide, associated with a sodium-depleted diet, and the ingested volumes of water and hypertonic saline were measured every $2 \mathrm{hr}$ (Fig. 5). In the control experiment, when isotonic saline was injected in place of furosemide in association with a sodium-depleted diet, OCT3 mutant and wild-type mice ingested comparable volumes of water and saline (Fig. 5A). Under the acute salt appetite condition induced by furosemide injection associated with a sodium-depleted diet, however, the OCT3 mutants showed an $\sim 40 \%$ increase in the ingestion of $0.3 \mathrm{M} \mathrm{NaCl}$ compared with the wild-type mice (Fig. $5 B$ ). This abnormal ingestion of hypertonic saline was maintained when furosemide was associated with conventional 
A

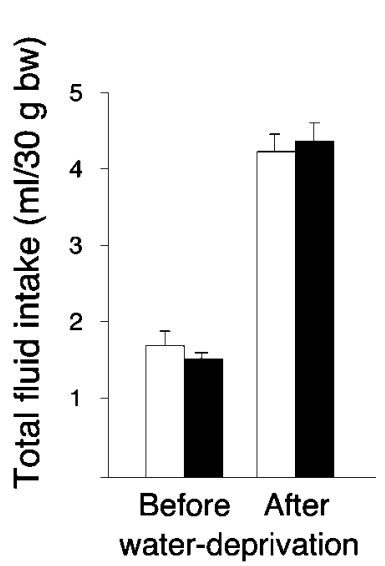

B

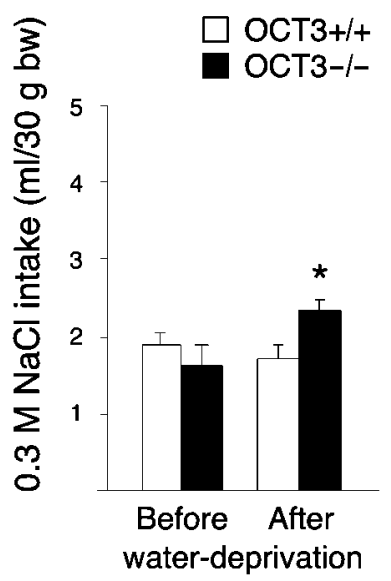

Figure 4. The $0 \mathrm{CT} 3 / \mathrm{Sl} 22 \mathrm{a} 3$ mutants show an increase in ingestion of hypertonic saline under dehydrated conditions. Total fluid intake $(A)$ and $0.3 \mathrm{M} \mathrm{NaCl}$ intake $(B)$ were measured for $6 \mathrm{hr}$ before and after $24 \mathrm{hr}$ water deprivation in $0 \mathrm{CT} 3-/-$ and control mice (mean + SEM; $n=8)$. ANOVA followed by Tukey test: ${ }^{*} p<0.05,+1+$ versus $-1-$ mice.

sodium-containing food (Fig. 5C). Concentrations of electrolytes in the plasma after salt deprivation were normal and comparable in wild-type and mutant mice $(n=6): 148.5 \pm 1.4$ and $149.8 \pm$ 1.4 for $\mathrm{Na}^{+} ; 110.3 \pm 1.2$ and $112.0 \pm 1.7$ for $\mathrm{Cl}^{-}$. This shows that under these conditions the null mutants regulate sodium excretion normally and that the alterations in neural response and salt-ingestion behavior observed in these animals stem from a defect in sensing or in response to variations in osmolarity.

\section{OCT3/Slc22a3-deficient mice show an abnormal decrease of}

Fos-immunoreactivity induction in the SFO

The SFO, an osmosensitive structure, is among the major sites of OCT3 expression. We thus examined next the effects of salt deprivation on the expression of the protein c-Fos, an indicator of central neural response to diverse excitatory stimuli, including changes in the extracellular fluid balance such as hyperosmolarity and hypovolemia (Sagar et al., 1988; Lane et al., 1997; Carlson et al., 1998; Thunhorst et al., 1998; Sunn et al., 2002). Figure 6 shows the evaluation of the number of Fos-immunopositive cells in two osmosensitive structures, SFO and OVLT, under normal and salt-deprived conditions. In basal conditions, few Fosimmunopositive cells were detected in the two regions examined in OCT3 knock-out and wild-type mice. After $24 \mathrm{hr}$ of salt deprivation (furosemide injection and sodium-depleted diet), the number of Fos-immunopositive cells was significantly increased in both SFO and OVLT in both types of mice (Fig. 6A, $B$ ). In the SFO, however, an approximately threefold decrease in the number of Fos-immunopositive cells was observed in OCT3 mutants as compared with wild-type mice. These results demonstrate an alteration of the cellular response to osmotic changes in this structure in OCT3-deficient mice. In contrast, in the OVLT, which does not express OCT3, the increase in Fosimmunopositive cells was comparable between the two genotypes (Fig. 6B).

\section{Discussion}

Concerted sodium and water balance regulation is a complex function implicating osmoreceptors for blood-borne information located in the anterior hypothalamus, such as the sensory CVOs, as well as secondary neural circuits in forebrain and hind-

\section{$0.3 \mathrm{M} \mathrm{NaCl}$ intake Water intake}

\section{A Saline injection + sodium-depleted diet}

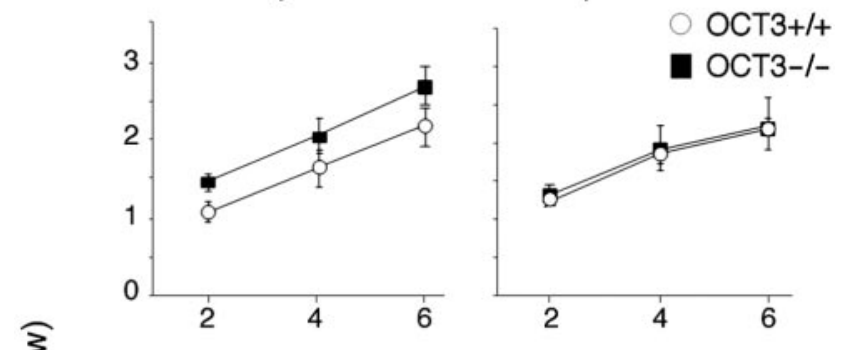

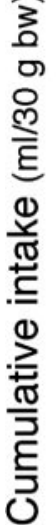

B Furosemide injection + sodium-depleted diet

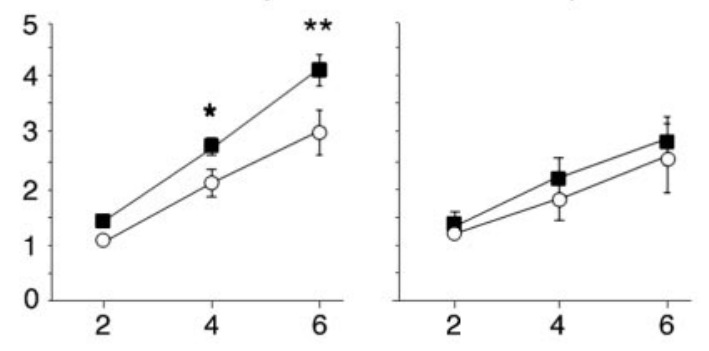

C Furosemide injection + normal diet

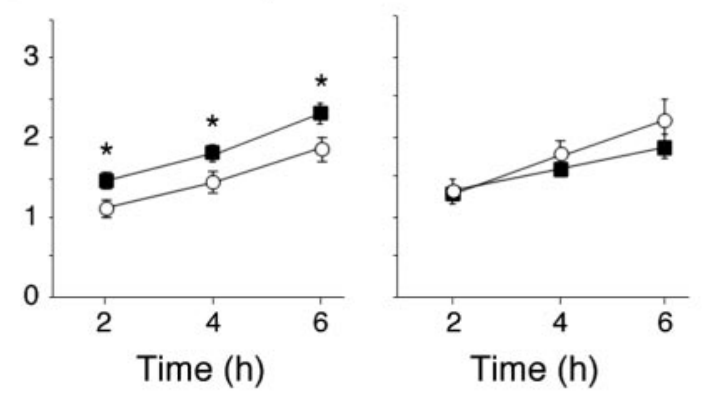

Figure 5. The $0 \mathrm{CT} 3 / \mathrm{SIC} 22 \mathrm{a} 3$ mutants show an increase in ingestion of hypertonic saline under acute salt appetite condition. The animals $(n=6-8)$ were sequentially submitted to a sodium-depleted diet associated with saline injections $(A)$, a sodium-depleted diet associated with furosemide injections $(B)$, and a normal diet associated with furosemide injections ( $C$ ). Mean cumulative intakes ( \pm SEM) of $0.3 \mathrm{M} \mathrm{NaCl}$ (left panel) and water (right panel) were measured every $2 \mathrm{hr}$ on the day after treatment in OCT3 $-/-$ and wild-type mice. ANOVA followed by Tukey test: ${ }^{*} p<0.05 ;{ }^{* *} p<0.01$.

brain, all of which are richly interconnected (Ferguson and Bains, 1996; Bourque and Oliet, 1997; Johnson and Thunhorst, 1997; Fitzsimons, 1998). We found OCT3 expressed predominantly in two regions displaying intrinsic sensitivity to osmolarity, SFO and $\mathrm{AP}$, and to a lower extent, in other osmosensitive or relay regions such as MPO, SON, PVN, and SOL. Expression of OCT3 in AP was also reported recently at the mRNA level by Haag et al. (2004). As suggested by this distribution, we found in mice lacking this transporter an abnormal salt-ingestion behavior, i.e., a marked increased preference for hypertonic saline, under both sodium depletion and water deprivation conditions. This indicates that the presence of OCT3 is required for the correct behavioral responses to environmentally induced variations in osmolarity. In several osmosensitive or relay regions, increase in neuronal activity has been previously correlated with a strong induction of c-Fos protein, establishing this marker as a reliable indicator of functional activation in these specific structures. In particular, acute sodium depletion provoked by administration of diuretics is known to dramatically increase c-Fos expression in 
A

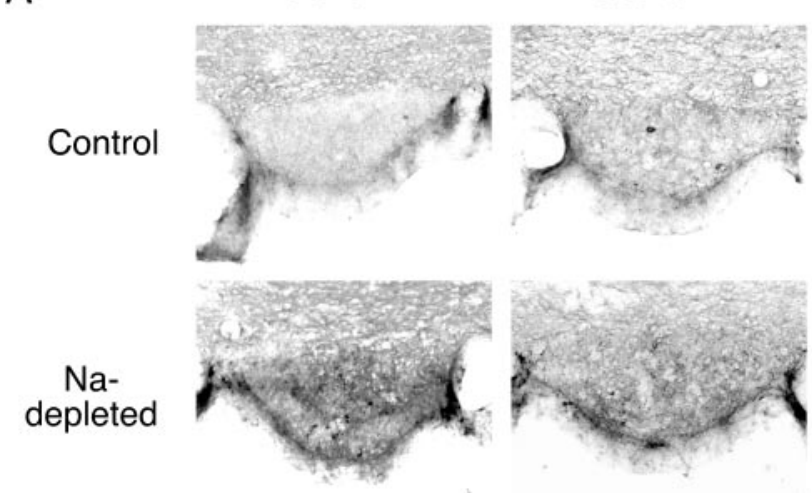

B
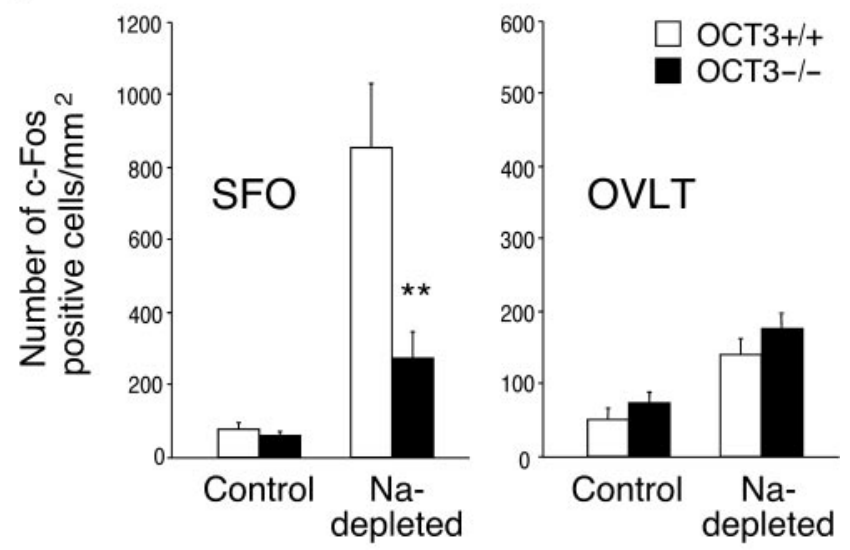

Figure 6. Alterations of c-Fos expression in $\mathrm{SFO}$ of $0 \mathrm{CT} 3 / \mathrm{SI} 22 \mathrm{a} 3$ mutant mice under conditions of salt deprivation. Wild-type and mutant mice were placed on a low sodium diet and injected with furosemide to induce sodium depletion. $A$, C-Fos expression in SFO of saltdeprived wild-type or mutant mice. $B$, Mean number ( \pm SEM) of c-Fos-expressing cells per square millimeter after $24 \mathrm{hr}$ of salt deprivation $(n=4)$, showing significantly decreased c-Fos induction in SFO but not OVLT of mutant mice. Student's $t$ test: ${ }^{* *} p<0.01$.

SFO, OVLT, MPO, SON, and PVN of rodents (Lane et al., 1997; Thunhorst et al., 1998). We thus searched for modifications of this functional response by quantitating the number of c-Fosexpressing cells in the SFO, in which OCT3 is highly expressed, in mice exposed to salt deprivation. Under this condition, we found that the intensity of c-Fos induction in SFO was decreased significantly in OCT3/Slc22a3-deficient mice in comparison with wild-type animals, reflecting a blunted neural response in this structure. Taken together, these findings constitute the first example of the involvement of an OCT in central functions and bring to light an unsuspected role for OCT3 in brain structures implicated in osmoreception and processing of osmotic information.

Similar examples of altered salt appetite have been reported previously in rodents. Lesions of the SFO have been shown to provoke a marked reduction of salt appetite after sodium depletion, whereas surgical ablation of AP, on the contrary, can significantly increase salt appetite (Johnson and Thunhorst, 1997). Increased hypertonic saline ingestion has also been observed in mouse mutant models with abnormal neuroendocrine signaling such as oxytocin deficiency (Puryear et al., 2001) and angiotensin II overexpression (Morimoto et al., 2002), as well as in mice deficient for an ionic channel highly expressed in CVOs (Watanabe et al., 2000).
The precise role of OCT3 in the neural response of the SFO during salt deprivation remains unclear. Our data suggest that the modifications of normal salt-ingestion behavior found in the mutants are the direct consequence of the impaired functional response of the SFO, an osmosensitive structure that expresses OCT3 at a high level. Still, although OCT3 activity is clearly required for a correct response of the SFO, it may also be needed for activation of secondary neural circuits implicated in the response, or even to ensure proper neurotransmission between some of the osmosensitive structures and relay regions.

SFO neurons have been shown to display intrinsic sensitivity to variations in extracellular osmotic pressure. The underlying primary mechanism has been suggested to be the activation of ionic channels, similar to that described for SON neurons, i.e., activation of mechanosensitive cationic channels in response to cell shrinkage, in turn regulating membrane potential, and action potential discharge (Wells, 1998; Anderson et al., 2000). For SFO neurons, however, the intrinsic conductance has not yet been identified. This response is also submitted to extensive control by secondary neural circuits and neuroendocrine signaling (Johnson and Thunhorst, 1997; Fitzsimons, 1998). OCT3 is a sodiumindependent transporter that transports organic cationic substances, mostly of exogenous origin, one exception of which is aminergic transmitters. Previous pharmacological studies in heterologous expression systems have shown that rat OCT3 can transport dopamine (Wu et al., 1998), whereas the human ortholog, extraneuronal monoamine transporter, can transport NA, 5-HT (Grundemann et al., 1998b), and histamine (Grundemann et al., 1999), suggesting that this transporter could participate in monoamine homeostasis in vivo. It thus seems unlikely that OCT 3 could be implicated per se in osmolarity sensing but more probable that it could play a role in modulation of the primary neural response, either within the SFO or by afferent connections. Several forebrain regions implicated in relaying osmoregulatory responses, like the MPO, the SON, and the magnocellular division of the PVN, express OCT3 at a low level. Therefore, the possibility that perturbations of the activity of these structures could contribute to some extent to the behavioral alterations observed in the mutants cannot be excluded. To address this issue, further neurochemical and behavioral investigations will be needed to determine whether aminergic neurotransmission is altered in the neural circuits that regulate salt and water ingestion in OCT3/Slc22a3 knock-out mice.

Finally, in addition to high level expression in some regions implicated in osmoregulation, OCT3 protein expression was also detected in other regions throughout rat brain, although with lesser intensity. This distribution includes regions that have been shown previously to express the corresponding mRNA, i.e., cerebral cortex, hippocampus, pontine nucleus, and cerebellum $(\mathrm{Wu}$ et al., 1998), but extends widely beyond these locations and covers all main regions of the brain. In our studies, OCT3 was located mostly in neurons, with the exception of ependymal cells of the SCO and pinealocytes. Moreover, under our conditions, brain astrocytes did not express detectable levels of OCT3. This contradicts previous reports of the presence of Uptake 2 and OCTs in human glioma cells and cultured rat astrocytes (Russ et al., 1996; Streich et al., 1996; Schomig et al., 1998; Hayer-Zillgen et al., 2002). These previous results led to the assumption that in vivo, in normal brain OCTs are located in astrocytes, which is not the case, as shown here. This discrepancy may reflect the disruption, in exvivo experimental systems, of environmental regulatory cues controlling the expression of these transporters.

To summarize, our results provide evidence for a major role of 
OCT3 (OCT3/Slc22a3) in the CNS. We show that OCT3 is expressed predominantly in regions that are implicated in sensing changes in blood osmolarity and regulation of salt and water ingestion and that the presence of this transporter is critical for the correct neural and behavioral responses to environmentally induced variations in osmolarity. This is the first description of the involvement of an OCT in central function in vivo, intimately linked to the particular distribution profile of OCT3. Undoubtedly, exploration of the role of other OCT members in brain will reveal diverse and unexpected functions for this complex and pleiotropic family.

\section{References}

Anderson JW, Washburn DL, Ferguson AV (2000) Intrinsic osmosensitivity of subfornical organ neurons. Neuroscience 100:539-547.

Bourque CW, Oliet SH (1997) Osmoreceptors in the central nervous system. Annu Rev Physiol 59:601-619.

Busch AE, Karbach U, Miska D, Gorboulev V, Akhoundova A, Volk C, Arndt P, Ulzheimer JC, Sonders MS, Baumann C, Waldegger S, Lang F, Koepsell H (1998) Human neurons express the polyspecific cation transporter hOCT2, which translocates monoamine neurotransmitters, amantadine, and memantine. Mol Pharmacol 54:342-352.

Carlson SH, Collister JP, Osborn JW (1998) The area postrema modulates hypothalamic fos responses to intragastric hypertonic saline in conscious rats. Am J Physiol 275:R1921-1927.

Ferguson AV, Bains JS (1996) Electrophysiology of the circumventricular organs. Front Neuroendocrinol 17:440-475.

Fitzsimons JT (1998) Angiotensin, thirst, and sodium appetite. Physiol Rev 78:583-686.

Friedgen B, Wolfel R, Russ H, Schomig E, Graefe KH (1996) The role of extraneuronal amine transport systems for the removal of extracellular catecholamines in the rabbit. Naunyn Schmiedebergs Arch Pharmacol 354:275-286.

Gorboulev V, Ulzheimer JC, Akhoundova A, Ulzheimer-Teuber I, Karbach U, Quester S, Baumann C, Lang F, Busch AE, Koepsell H (1997) Cloning and characterization of two human polyspecific organic cation transporters. DNA Cell Biol 16:871-881.

Grundemann D, Babin-Ebell J, Martel F, Ording N, Schmidt A, Schomig E (1997) Primary structure and functional expression of the apical organic cation transporter from kidney epithelial LLC-PK1 cells. J Biol Chem 272:10408-10413.

Grundemann D, Koster S, Kiefer N, Breidert T, Engelhardt M, Spitzenberger F, Obermuller N, Schomig E (1998a) Transport of monoamine transmitters by the organic cation transporter type 2, OCT2. J Biol Chem 273:30915-30920.

Grundemann D, Schechinger B, Rappold GA, Schomig E (1998b) Molecular identification of the corticosterone-sensitive extraneuronal catecholamine transporter. Nat Neurosci 1:349-351.

Grundemann D, Liebich G, Kiefer N, Koster S, Schomig E (1999) Selective substrates for non-neuronal monoamine transporters. Mol Pharmacol 56:1-10.

Haag C (2004) The localisation of the extraneuronal monoamine transporter (EMT) in rat brain. J Neurochem 88:291-297.

Hayer-Zillgen M, Bruss M, Bonisch H (2002) Expression and pharmacological profile of the human organic cation transporters hOCT1, hOCT2 and hOCT3. Br J Pharmacol 136:829-836.

Hendley ED, Taylor KM, Snyder SH (1970) ${ }^{3} \mathrm{H}$-normetanephrine uptake in rat brain slices. Relationship to extraneuronal accumulation of norepinephrine. Eur J Pharmacol 12:167-179.

Iversen LL (1965) The uptake of catecholamines at high perfusion concentrations in the rat isolated heart: a novel catecholamine uptake process. Br J Pharmacol 25:18-33.

Johnson AK, Thunhorst RL (1997) The neuroendocrinology of thirst and salt appetite: visceral sensory signals and mechanisms of central integration. Front Neuroendocrinol 18:292-353.

Koepsell H (1998) Organic cation transporters in intestine, kidney, liver, and brain. Annu Rev Physiol 60:243-266.

Lane JM, Herbert J, Fitzsimons JT (1997) Increased sodium appetite stimulates c-fos expression in the organum vasculosum of the lamina terminalis. Neuroscience 78:1167-1176.

Morimoto S, Cassell MD, Sigmund CD (2002) Glia- and neuron-specific expression of the renin-angiotensin system in brain alters blood pressure, water intake, and salt preference. J Biol Chem 277:33235-33241.

Morimoto R, Hayashi M, Yatsushiro S, Otsuka M, Yamamoto A, Moriyama Y (2003) Co-expression of vesicular glutamate transporters (VGLUT1 and VGLUT2) and their association with synaptic-like microvesicles in rat pinealocytes. J Neurochem 84:382-391.

Puryear R, Rigatto KV, Amico JA, Morris M (2001) Enhanced salt intake in oxytocin deficient mice. Exp Neurol 171:323-328.

Russ H, Staust K, Martel F, Gliese M, Schomig E (1996) The extraneuronal transporter for monoamine transmitters exists in cells derived from human central nervous system glia. Eur J Neurosci 8:1256-1264.

Sagar SM, Sharp FR, Curran T (1988) Expression of c-fos protein in brain: metabolic mapping at the cellular level. Science 240:1328-1331.

Schomig E, Russ H, Staudt K, Martel F, Gliese M, Grundemann D (1998) The extraneuronal monoamine transporter exists in human central nervous system glia. Adv Pharmacol 42:356-359.

Streich S, Bruss M, Bonisch H (1996) Expression of the extraneuronal monoamine transporter (uptake2) in human glioma cells. Naunyn Schmiedebergs Arch Pharmacol 353:328-333.

Sunn N, Egli M, Burazin TC, Burns P, Colvill L, Davern P, Denton DA, Oldfield BJ, Weisinger RS, Rauch M, Schmid HA, McKinley MJ (2002) Circulating relaxin acts on subfornical organ neurons to stimulate water drinking in the rat. Proc Natl Acad Sci USA 99:1701-1706.

Thunhorst RL, Xu Z, Cicha MZ, Zardetto-Smith AM, Johnson AK (1998) Fos expression in rat brain during depletion-induced thirst and salt appetite. Am J Physiol 274:R1807-1814.

Trendelenburg U (1988) The extraneuronal uptake and metabolism of catecholamines. In: Handbook of experimental pharmacology (Trendelenburg U, Weiner N, eds), pp 279-319. Berlin: Springer.

Watanabe E, Fujikawa A, Matsunaga H, Yasoshima Y, Sako N, Yamamoto T, Saegusa C, Noda M (2000) Nav2/NaG channel is involved in control of salt-intake behavior in the CNS. J Neurosci 20:7743-7751.

Wells T (1998) Vesicular osmometers, vasopression secretion and aquaporin-4: a new mechanism for osmoreception? Mol Cell Endocrinol 136:103-107.

Wilson VG, Grohmann M, Trendelenburg U (1988) The uptake and $\mathrm{O}$-methylation of ${ }^{3} \mathrm{H}-(+/)$-isoprenaline in rat cerebral cortex slices. Naunyn Schmiedebergs Arch Pharmacol 337:397-405.

Wu X, Kekuda R, Huang W, Fei YJ, Leibach FH, Chen J, Conway SJ, Ganapathy V (1998) Identity of the organic cation transporter OCT3 as the extraneuronal monoamine transporter (uptake2) and evidence for the expression of the transporter in the brain. J Biol Chem 273:32776-32786.

Zwart R, Verhaagh S, Buitelaar M, Popp-Snijders C, Barlow DP (2001) Impaired activity of the extraneuronal monoamine transporter system known as uptake-2 in Orct3/Slc22a3-deficient mice. Mol Cell Biol 21: 4188-4196. 